\title{
Synthesis of (-)-Himandrine
}

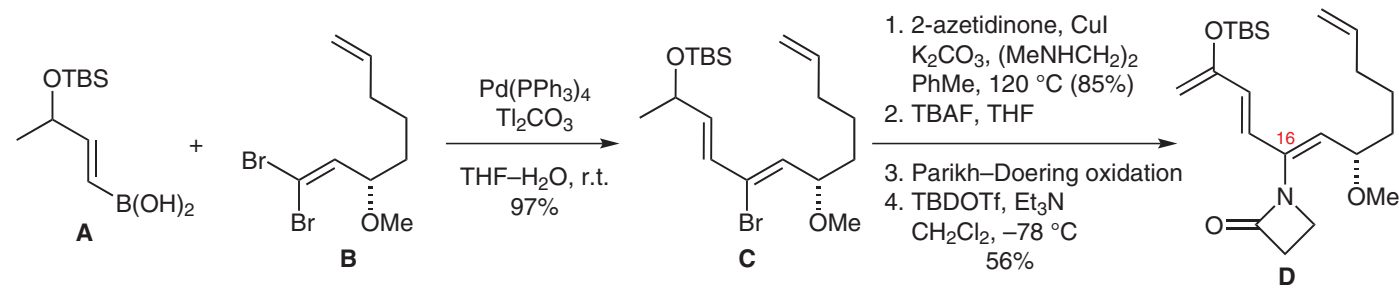

\section{Key words}

himandrine

intramolecular Diels-Alder reaction

\section{Suzuki coupling}

cross-metathesis

amination

annulation

palladium acrolein, Grubbs II (10 mol\%) $85 \%$ $\mathrm{CH}_{2} \mathrm{Cl}_{2}$, r.t.
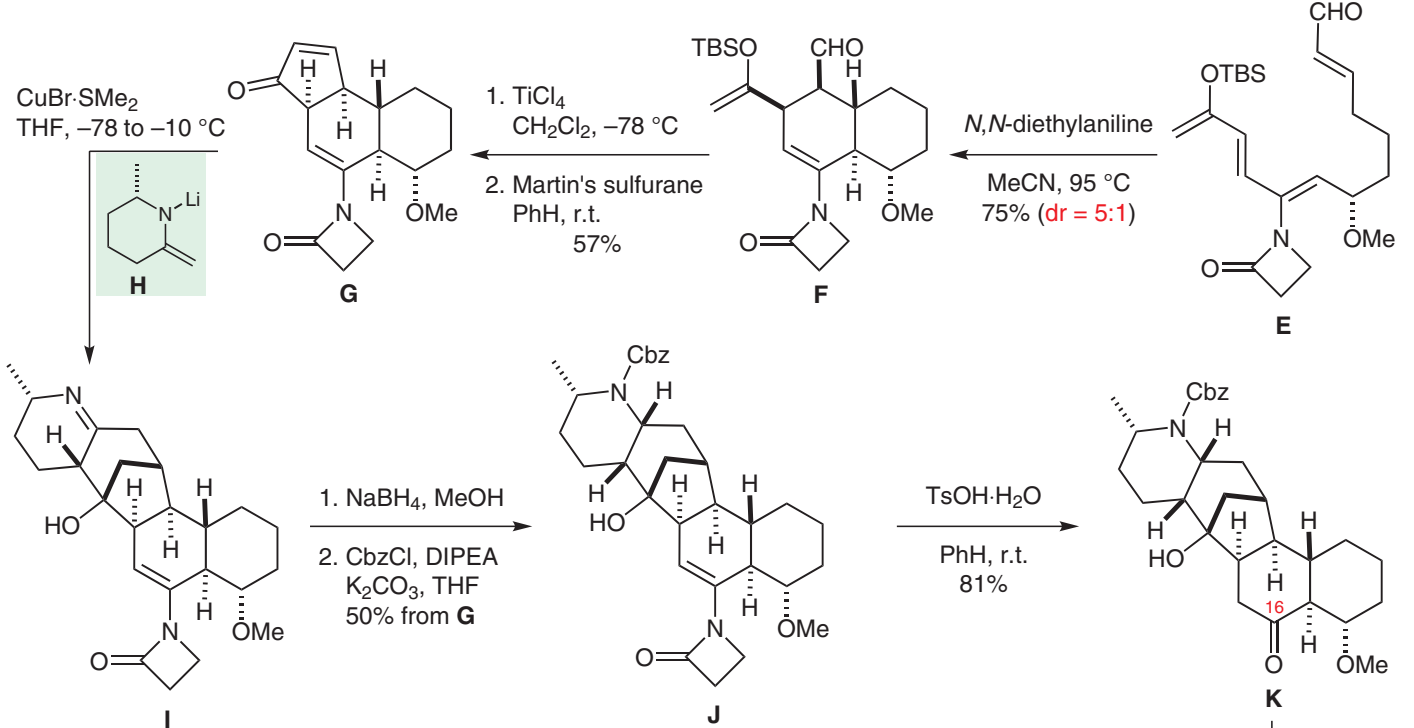

1. $\mathrm{NaBH}_{4}, \mathrm{MeOH}$
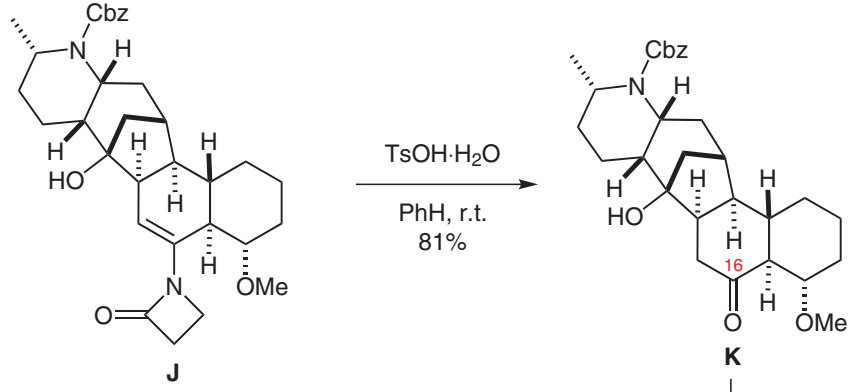

\section{CbzCl, DIPEA}

$50 \%$ from $\mathbf{G}$

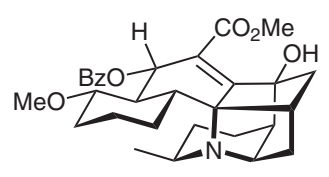

(-)-Himandrine

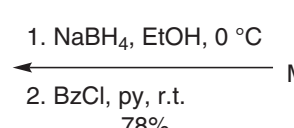

$78 \%$

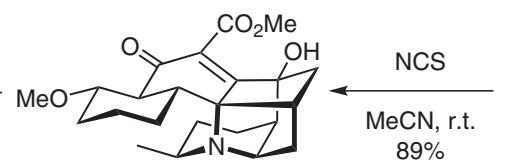

M

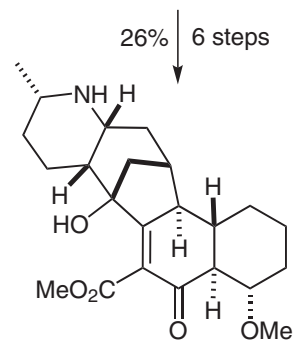

L

Significance: (-)-Himandrine was isolated from the bark of the tree Galbulimima belgraveana.

Eight of the ten stereogenic centers were created by diastereoselective processes starting from just two stereogenic centers in fragments $\mathbf{B}$ and $\mathbf{H}$.
Comment: The 2-azetidinone moiety at C16 served a dual role: it facilitated the Diels-Alder reaction by providing a $2-N$-acylaminodiene $\mathbf{E}$ with a greater preference for the $s$-cis conformation and it served as a latent C16 carbonyl $(\mathbf{J} \rightarrow \mathbf{K})$.

SYNFACTS Contributors: Philip Kocienski 